\title{
Mobile Application Design Emergency Medical Call for the Deaf using UCD Method
}

\author{
https://doi.org/10.3991/ijim.v12i3.8754 \\ Risald, Suyoto $\left.{ }^{\bowtie}\right)$, Albertus Joko Santoso \\ Universitas Atma Jaya Yogyakarta, Yogyakarta, Indonesia \\ Suyoto@staff.uajy.ac.id
}

\begin{abstract}
Deaf or hearing loss is a condition of inability to hear something, either totally or partially. Hearing loss greatly affects the life of a person in communicating with the people around him. Deaf people will be very difficult when in a medical emergency, this is because the medical emergency situation requires fast action. The Healthy Phone application is a mobile medical emergency call application that can help people with hearing impaired when in emergency situations. With the Healthy Phone application, the user only needs to select an icon that suits the situation encountered in touchscreen mobile device then the message will be sent to the nearest hospital. To search for icons corresponding to emergencies, the User Centered Design (UCD) method is used. This application is very helpful for deaf people because this application does not require audio communication and user location is also sent automatically to the nearest hospital. The results were analyzed using four emergency event scenarios with a total score of $87 \%$ and an average user time of less than $0: 42 \mathrm{sec}$ indicating that the study was successful in designing a mobile medical emergency call application according to user requirements.
\end{abstract}

Keywords-Deaf, User-Centered Design, Emergency call, The Iconography interface

\section{Introduction}

Deaf or hearing loss is a condition of inability to hear something, either totally or partially. Hearing loss usually occurs due to heredity or it could be due to age factor. Hearing disorders are grouped into 3 ie severe disturbances, moderate disturbance, and mild disturbance[1].

Hearing loss has a profound impact on the quality of life of the sufferer which resulted in them never knowing what a sound is so that they are also unable to produce sound [1][2]. In everyday life, the sound is the main component in interacting and communicating with the people around. This is also a problem when deaf people are in emergency situations [3].

The emergency can be defined as a sudden or unexpected situation with a risk to health, life, property or environment that requires action to repair or protect [4]. In most countries, there are services associated with each emergency control center in 
response to any type of emergency, usually firefighters, police and medical emergencies [5]. Medical emergencies are emergency situations that are related to health and require rapid action [6]. One of the actions that need to be done is the use of mobile devices to make phone calls to the hospital. The development of mobile devices now makes it easy to build mobile apps that support users efficiently in some daily activities [7] [8] [9]. A situation that benefits everyone where people easily make emergency calls because all the features are available on every phone.

Emergency situations will be difficult for some people who have limitations such as people with disabilities or people who have a traumatic situation to make an emergency call [3][10]. For example, deaf people who are unable to communicate well through voice calls. Moreover, other examples of parents or people who have a certain trauma will be difficult to articulate words [3]. To help hearing-impaired people who have problems during an emergency condition the authors designed a medical emergency call medical app for deaf people using the user-centered design method (UCD).

With the mobile medical emergency call application for deaf people using UCD method, it is expected that deaf people to contact the nearest hospital from the scene without audio communication, the user only needs to choose the icon that suits the situation faced when the incident occurred. After that, they simply clicked a few boxes to answer simple questions like the number of victims in the incident. The result of this selection process is the message sent to the nearest hospital containing the report corresponding to the selected information, along with the user profile and the coordinates of the caller. This app has the potential to be very important for deaf people, as well as in a panic situation or some event that suddenly makes it difficult to articulate the words.

\section{$2 \quad$ Literature Review and Related Works}

There are some previous studies that can be used as a reference so that mobile medical emergency call applications for deaf people using UCD method can be proposed in this study. The study titled SOSPhone: A Mobile Application For Emergency Calls [3]. In research Paredes et al developed prototype emergency calling apps for people with disabilities (deaf) and parents, in the study it was explained that parents and deaf are difficult to cope with emergencies due to limitations in communicating via telephone calls.

Research on universal access to emergency services using mobile apps is also a hot topic [11]. In a study a mobile system was created to handle communications between emergency medical responders and deaf people, to improve communication with emergency language transactions to interpret sign language [11].

The emergency system has been used by deaf people as another perspective and has used many types of technology [12]. The use of teletypewriter (TTY) mode to access to emergency services by deaf people is not so recommended. In addition, other studies have shown the use of SMS and TTY as a preferential mechanism by deaf users to communicate. Regarding the preferences of deaf people in the UK, Pill- 
ing and Barrett concluded in their research that participants used some form of text communication, including SMS, TTY, fax, and email for specific purposes [13]. In addition, most people prefer text messages only or videos that are assembled from modular segments, which describe sustainable sign language videos [13].

However, other projects focus on translator services, to mediate communications in emergencies [14]. In this study, they realized that the most common form of communication is SMS messaging, with the exception of Spanish and Greek using the REACH112 system prototype. Complementary, and focused only on the United States [15].

A study entitled User-Centred Design with Visually Impaired Pupils: A Case Study of a Game Editor for Orientation and Mobility Training [16], in a study by Mattheiss et al, they made a game for orientation and mobility training for the blind using the UCD method.

Research entitled Design and Evaluation Of A User-Centered Interface To Model Scenarios On Driving Simulators [17], in this study, Bhatti et al studied about modeling scenarios on the driving simulator using UCD method. Research entitled Accessible Options For Deaf People In E-Learning Platforms: Technology Solutions For Sign Language Translation [18], Martins et al present a study of potential technological solutions to improve the communication process for deaf people in Platform learning through translations of Sign Language (SL).

From various existing research, the authors conclude that the use of text messages cannot be applied to people with hearing impairment so that required an application that can work quickly and easily understood by every user who experienced an emergency situation.

\section{$3 \quad$ Method and Materials}

This study focuses on the design of mobile medical emergency call applications for deaf people using user-centered design methods. stages performed in this study can be seen in Figure 1.

\subsection{Data collection}

This stage consists of 2 parts: literature study and field study. The literature study is conducted by searching for supporting research literature such as reading the source of related libraries from internet, thesis, journals related to the research topic. The field study was conducted by observing and interviewing at SLB B Karnnamanohara Yogyakarta. In the field study, observations were made to 20 students to know the characteristics of the users. In addition, interviews were also conducted with parents and teachers to obtain supporting data. 


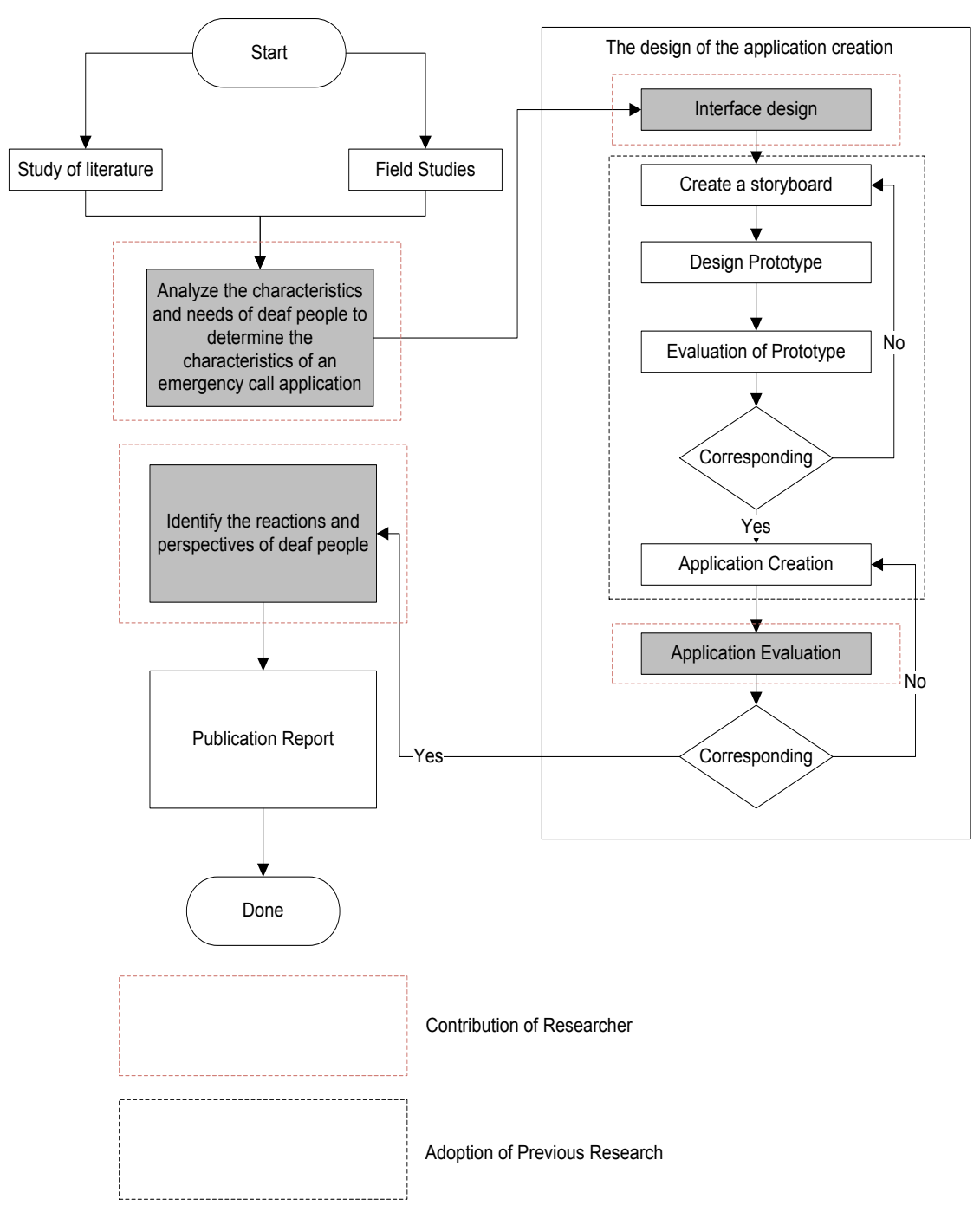

Fig. 1. Research Flow Diagram

\subsection{Stage of Needs Analysis}

This stage is the stage of needs analysis which includes two activities that are identifying the characteristics and needs of the user for mobile applications that will be made. The process at the analysis stage can be seen in Figure 2: 


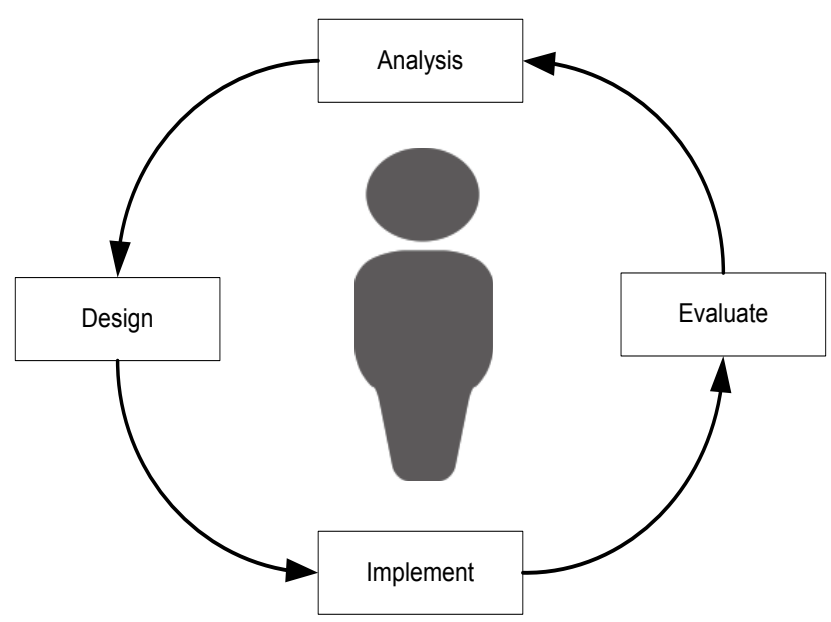

Fig. 2. UCD Process

Plan the human-centered design process. In this process, every work of our application interface centered on user needs [19], in this case, is deaf people. In this case, we will involve the deaf people at $S L B$ B Karnnamanohara to ask their opinions or suggestions about the application interface.

Understand Specifying the Context of Use. The basis of any UCD process is to understand the users of the intended product and their usage environment. Therefore, the typical UCD process begins with identifying users, it also includes all stakeholders, or indirect users, all associated with the system [20]. At this stage too, we identify user characteristics and user groups, possible characteristics, following ISO definition, skills, education, age, etc [20].

Specifying the User Requirements. Basically at this stage is the stage of extracting information or data to collect the needs of the user, then after the information or data has been collected, the arrangement of information from the data needs of the user, the user needs are described into various forms or techniques, such as narration, or diagrams, etc [21].

Produce Design Solution. In this step, the first design was created. Sketches, simulations and other forms of prototypes used to make visible ideas and facilitate effective communication with users. This prevents the possible high costs and associated requirements for reworking the product in the next step of the life cycle. When design solutions are presented to users, they must also be allowed to perform tasks. The user feedback collected should be included in the improvement of the design solution. It should be iterated continuously until the design goals have been met [20].

Evaluating The Design. In the next activity, the design solution that the previous stage is evaluated. The goal is to generate feedback to further improve the product and to determine whether the design meets the specified user requirements, usability goals and in accordance with general usability guidelines. The UCD process cycle continues as long as usability purposes are not met [21]. 


\subsection{Results of Needs Analysis}

The use of text-based communication solutions cannot be applied to people with hearing-impaired because from birth the language used by them is sign language [22], and consequently, some of them are illiterate [23]. From the analysis that has been done with the needs of the user obtained some requirements that must be owned application to be made. The following are the common requirements that have been identified:

- The user interface should avoid using text to allow all users to access emergency service calls. The situation should be explained by large icons and easily accessed with high contrast. Icons should be selected from the symbology reference.

- Input information should be easy for people with mobility problems.

- This application should allow users to describe the situation in as much detail as possible, such as the number of victims and the additional information needed to follow.

- The use of network bandwidth should be reduced so that communication is faster in emergency situations.

- Locations that are automatically displayed so that users do not need to provide an address because coordinate directly sent to the hospital.

- User registration will complete caller identification and provide more information to prevent invalid calling.

\section{$4 \quad$ Result and Discussion}

\subsection{Healthy Phone Architecture}

The concept of the Healthy Phone app is the same as the concept of online taxi booking. Users in emergency situations send messages to the hospital using the app and the app will send a message to the hospital closest to the user's location Explanation of application concept can be seen in Figure 3.

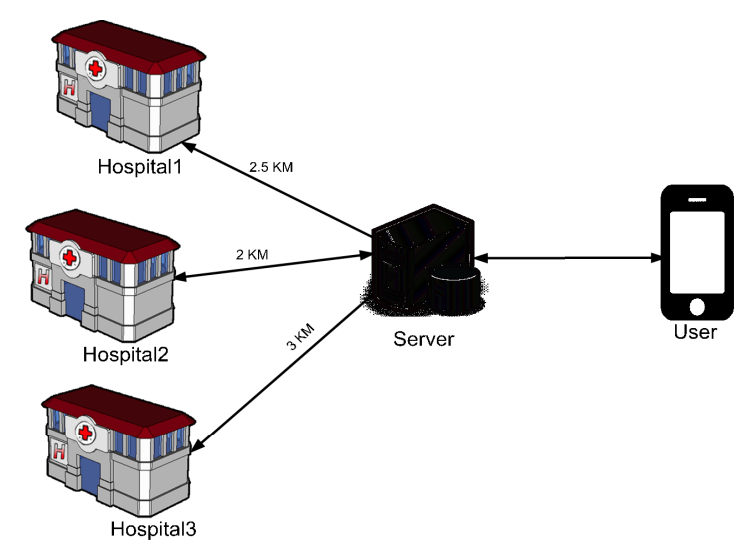

Fig. 3. Healthy Phone Architecture 


\subsection{Interface Design Healthy Phone}

The results of the identification that has been done and generate some requirements given by the user so that has been applied to the prototype mobile application Healthy Phone. The prototype of Healthy Phone phone application can be seen in Figure 4.

Figure 4 is the initial view when registered users open the Healthy Phone app. Users experiencing emergencies only need to tap images that match their current events. These emergency events can be experienced by the user itself or others around him.

In Figure 5 the user needs to fill in the event data such as the number of victims and additional information which is an optional option. The location shown here is the automatic location according to the user's position. Then the user simply presses "Send" then the message will be sent by the application to the nearest hospital.

In Figure 6 is a confirmation interface display containing event data received by the nearest hospital from where the user is located. The hospital only needs to press the "confirm" button as a notification that the hospital has confirmed the emergency and is ready to take action by sending the ambulance and medical equipment required.

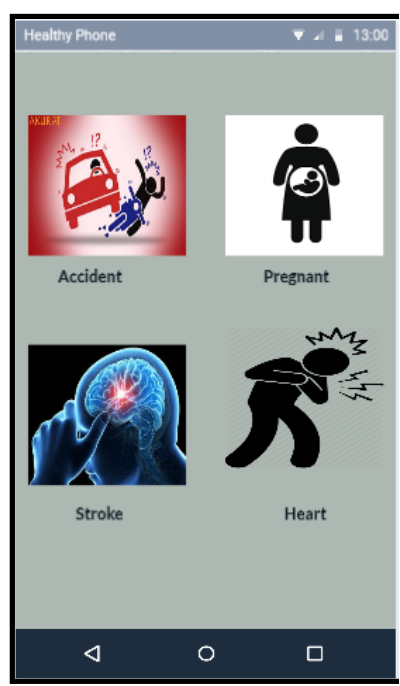

Fig. 4. Home Interface

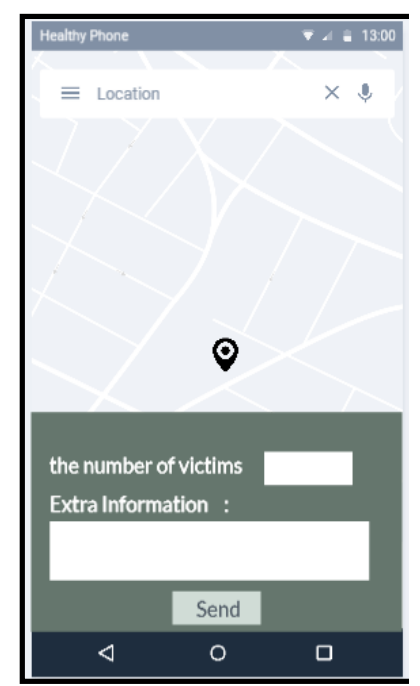

Fig. 5. Send Location Form

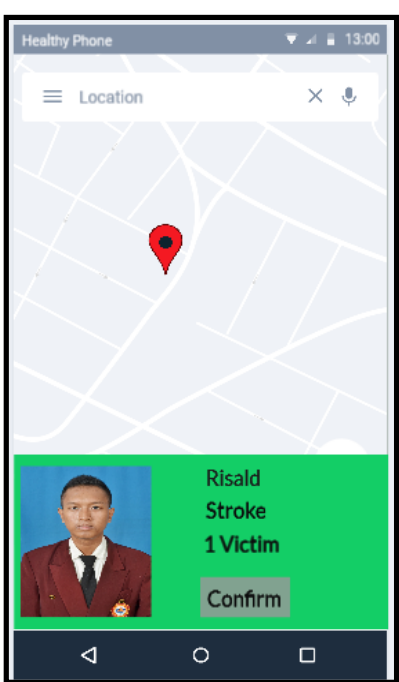

Fig. 6. Confirmation Form

\subsection{User Experiment}

To assess whether the Healthy Phone application is acceptable to users. The experiment was conducted by involving 20 students, three teachers and two parents from SLB B Karnnamanohara. From the first experiment, the user is given a video showing an emergency situation and they must describe the event into the application. There are four different emergency scenarios that we use as hypotheses: 
- S1: Two men who have an accident due to excess alcohol.

- S2: One person experiences shortness of breath and rapid heartbeat.

- S3: A woman who is pregnant and feels the contraction.

- S4: A middle-aged man who suffers from headaches and suddenly cannot speak.

The results obtained by only a handful of users are able to complete the call until it is over and within a less rapid timeframe if they are really in an emergency situation to operate the Healthy Phone app. The results of the experiments are summarized in Table 1 .

In the second experiment, the same scenario as the first experiment was performed and the results obtained were much better than the first experiment. In addition to more who successfully make calls correctly the time required is much faster. The results of the second experiment are summarized in Table 2.

Table 1. Summary of first experimental results.

\begin{tabular}{|l|c|c|c|c|c|}
\hline \multicolumn{1}{|c|}{ scenario } & S1 & S2 & S3 & S4 & Average \\
\hline Number of calls completed correctly & $7(28 \%)$ & $10(40 \%)$ & $12(48 \%)$ & $8(32 \%)$ & $9.25(37 \%)$ \\
\hline Average time to complete the call (min: sec) & $1: 35$ & $1: 15$ & $1: 25$ & $2: 00$ & 1.34 \\
\hline
\end{tabular}

Table 2. Summary of results of the second experiment

\begin{tabular}{|l|c|c|c|c|c|}
\hline \multicolumn{1}{|c|}{ scenario } & S1 & S2 & S3 & S4 & Average \\
\hline Number of calls completed correctly & $22(88 \%)$ & $23(92 \%)$ & $24(96 \%)$ & $18(72 \%)$ & $21,75(87 \%)$ \\
\hline Average time to complete the call (min: sec) & $0: 40$ & $0: 35$ & $0: 35$ & $1: 00$ & $0: 42$ \\
\hline
\end{tabular}

\section{Conclusion}

The Healthy Phone application has been designed to meet the objectives and purposes of this study using the UCD method. This system can be easily used by deaf users who are in emergency situations. This system is in accordance with its function and meets the needs of users in making emergency calls. The results were analyzed using four emergency event scenarios with a total score of $87 \%$ and an average user time of less than 0:42 sec indicating that the study was successful in designing a mobile medical emergency call application according to user requirements. From the experiments that have been done, there are obtained some input obtained from the user such as adding the victim awareness status and include icons that symbolize the short breath.

\section{References}

[1] P. H. Lena, W. R. Jimbara, and Suyoto, "Learning to Read and Identifies the Level of Hearing Disability Early Age Using a Mobile Learning Application," in Teaching and Learning in a Digital World. ICL 2017. Advances in Intelligent Systems and Computing, M. E. Auer., D. Guralnick., and I. Simonics., Eds. Springer, Cham, 2018, pp. 355-362. 
[2] E. E. Abdallah and E. Fayyoumi, “Assistive Technology for Deaf People Based on Android Platform,” Procedia Comput. Sci., vol. 94, no. Fnc, pp. 295-301, 2016.

[3] H. Paredes, B. Fonseca, M. Cabo, T. Pereira, and F. Fernandes, "SOSPhone: A mobile application for emergency calls," Univers. Access Inf. Soc., vol. 13, no. 3, pp. 277-290, 2014. https://doi.org/10.1007/s10209-013-0318-z

[4] S. H. Li, K. A. Cheng, W. H. Lu, and T. C. Lin, "Developing an active emergency medical service system based on WiMAX technology," J. Med. Syst., vol. 36, no. 5, pp. 31773193, 2012. https://doi.org/10.1007/s10916-011-9809-8

[5] B. N. Ong, M. P. Yip, S. Feng, R. Calhoun, H. W. Meischke, and S. P. Tu, "Barriers and facilitators to using 9-1-1 and emergency medical services in a limited English proficiency Chinese community," J. Immigr. Minor. Heal., vol. 14, no. 2, pp. 307-313, 2012. https://doi.org/10.1007/s10903-011-9449-6

[6] C. Subramaniam, H. Ali, and F. Mohd Shamsudin, "Initial emergency response performance of firefighters in Malaysia," Int. J. Public Sect. Manag., vol. 25, no. 1, pp. 64-73, 2012. https://doi.org/10.1108/09513551211200294

[7] B. M. C. Silva, J. J. P. C. Rodrigues, F. Canelo, I. M. C. Lopes, and J. Lloret, "Towards a cooperative security system for mobile-health applications," Electron. Commer. Res., no. $1,2014$.

[8] Suyoto, T. Prasetyaningrum, and R. M. Gregorius, "Design and Implementation of Mobile Leadership with Interactive Multimedia Approach," in Communications in Multimedia, Computer Graphics and Broadcasting. Communications in Computer and Information Science (CCIS), vol. 262, T. Kim., Ed. Springer, Berlin, Heidelberg, 2011, pp. 217-226.

[9] N. B. Nugraha, Suyoto, and Pranowo, "Mobile application development for smart tourist guide," Adv. Sci. Lett., pp. 2475-2477, 2017.

[10] R. Schnall et al., "A user-centered model for designing consumer mobile health (mHealth) applications (apps)," J. Biomed. Inform., vol. 60, pp. 243-251, 2016. https://doi.org/10.1016/j.jbi.2016.02.002

[11] F. Buttussi, V. Scienze, and M. Coppo, "Using Mobile Devices to Support Communication between Emergency Medical Responders and Deaf People,” pp. 7-16, 2010. https://doi.org/10.1145/1851600.1851605

[12] F. Vallières, E. McAuliffe, I. Palmer, E. Magbity, and A. Bangura, "Supporting \& Strengthening maternal, neonatal, and child health services using mobile phones in Sierra Leone: A Research Protocol," Harvard Africa Policy J., vol. 8, pp. 46-51, 2013.

[13] D. Pilling. and P. Barrett., "Text Communication Preferences of Deaf People in the United Kingdom," J. Deaf Stud. Deaf Educ., vol. 13, no. 1, pp. 92-103, 2008. https://doi.org/10.1093/deafed/enm034

[14] K. Alagappan, J. Rella, S. Bentley, M. Soto-Greene, and M. Martin, "Interpreter Services In Emergency Medicine,” JEM, vol. 38, no. 2, pp. 133-139, 2010.

[15] H. Mitchell, J. Johnson, and S. LaForce, "The human side of regulation: emergency alerts," in Proceedings of the 8th International Conference on Advances in Mobile Computing and Multimedia, 2010. https://doi.org/10.1145/1971519.1971551

[16] E. Mattheiss, G. Regal, D. Sellitsch, and M. Tscheligi, "User-centred design with visually impaired pupils: A case study of a game editor for orientation and mobility training," Int. J. Child-Computer Interact., vol. 11, pp. 12-18, 2017. https://doi.org/10.1016/j.ijcci. 2016.11.001

[17] G. Bhatti, R. Brémond, J. P. Jessel, N. T. Dang, F. Vienne, and G. Millet, "Design and evaluation of a user-centered interface to model scenarios on driving simulators," Transp. Res. Part C Emerg. Technol., vol. 50, pp. 3-12, 2015. https://doi.org/10.1016/j.trc. 2014.09.011 
[18] P. Martins, H. Rodrigues, T. Rocha, M. Francisco, and L. Morgado, "Accessible Options for Deaf People in e-Learning Platforms: Technology Solutions for Sign Language Translation,” Procedia Comput. Sci., vol. 67, pp. 263-272, 2015. https://doi.org/10.1016/ j.procs.2015.09.270

[19] L. A. Wardana, "Design Mobile Application of Marriage Counseling on the Catholic Church with UCD and Wireframe Method," Int. J. u- e-Serv. Sci. Technol., vol. 10, no. 1, pp. 153-162, 2017.

[20] J. Brunner, E. Chuang, C. Goldzweig, C. L. Cain, C. Sugar, and E. M. Yano, "Usercentered design to improve clinical decision support in primary care," Int. J. Med. Inform., 2017. https://doi.org/10.1016/j.ijmedinf.2017.05.004

[21] M. Schreuder et al., "User-centered design in the brain-computer interfaces-A case study," Artif. Intell. Med., vol. 59, no. 2, pp. 71-80, 2013. https://doi.org/10.1016/j.artmed. 2013.07.005

[22] L. J. Hubbard, E. D'Andrea., and L. A. Carman., "Promoting Best Practice for Perinatal Care of Deaf Women," Nurs. Women's Heal., vol. 22, no. 2, pp. 126-136, 2018. https://doi.org/10.1016/j.nwh.2018.02.002

[23] N. Fariña, J. Andoni, and M. Carreiras, "Phonological and orthographic coding in deaf skilled readers," vol. 168, pp. 27-33, 2017.

\section{Authors}

Risald is a Master of Informatics Engineering Student at Universitas Atma Jaya Yogyakarta, Yogyakarta, Indonesia. He is a scholar of the Stikom Uyelindo Kupang. His research interests are the mobile app, web programming, and user interface design.

Suyoto is Professor in Department of Informatics Engineering at Universitas Atma Jaya Yogyakarta, Yogyakarta, Indonesia. He has more than seventeen years of teaching experience. He received his Ph.D. in 2000 from the National University of Malaysia, Malaysia. His research interests are multimedia, computer graphics, visualization, mobile application and artificial intelligence.

Albertus Joko Santoso is currently a senior lecturer at Department of Informatics Engineering at Universitas Atma Jaya Yogyakarta, Yogyakarta, Indonesia. He got the Ph.D. from Gadjah Mada University in 2012. His research interests include Image Processing, Pattern Recognition and Intelligent System.

Article submitted 19 April 2018. Resubmitted 27 April 2018. Final acceptance 08 May 2018. Final version published as submitted by the authors. 